\title{
Genetic variation of trypsin and chymotrypsin inhibitors in pigeonpea [Cajanus cajan (L.) Millsp.] and its wild relatives
}

\begin{abstract}
Variation in the trypsin inhibitors (TIs) and the chymotrypsin inhibitors (CIs) among 69 pigeonpea [ $\mathrm{Caj}$ anus cajan (L.) Millsp.] strains from a wide geographical distribution and among 17 accessions representing seven wild Cajanus species was studied by electrophoretic banding pattern comparisons and by spectrophotometric activity assays. The TI and CI electrophoretic migration patterns among the pigeonpea strains were highly uniform but varied in the inhibitor band intensities. The migration patterns of the inhibitors in the wild Cajanus species were highly species specific. The mean TI activity of pigeonpea strains (2279 units) was significantly higher than that of the wild Cajanus species (1407 units). However, the mean $\mathrm{CI}$ activity in the pigeonpea strains (62 units) was much lower than that in the wild species (162 units). Kenya 2 and ICP 9151 were the lowest and the highest, respectively, in both the TI and CI activities among all the pigeonpea strains used in this study. A highly-significant positive correlation was observed between the TI and CI activities. The Bowman-Birk type inhibitors with both $\mathrm{TI}$ and $\mathrm{CI}$ activities were identified in all the pigeonpea strains and also in the accessions of all the wild species except $C$. volubilis (Blanco) Blanco. The C. volubilis accession ICPW 169 was found to be 'null' for both CI bands and CI activity. Environment, strain, and environment $\times$ strain interaction showed highly-significant effects on both the TI and CI activities. Growing the pigeonpea strains at a different environment from their area of adaptation increased TI and CI activities and also altered the maturity period.
\end{abstract}

Key words Pigeonpea - Wild Cajanus species

Trypsin inhibitors · Chymotrypsin inhibitors

Non-denaturing PAGE · Activity staining - Environment

Communicated by A. L. Kahler

K. P. Kollipara $\cdot$ L. Singh ${ }^{1} \cdot$ T. Hymowitz $(区)$

Department of Agronomy, University of Illinois, Urbana, IL 61801, USA

Present address:

${ }^{1}$ International Crops Research Institute for the Semi-Arid Tropics (ICRISAT), Patancheru, A.P. 502324, India

\section{Introduction}

Pigeonpea [Cajanus cajan (L.) Millsp.] is cultivated in the semi-arid tropics of Asia, Africa, and the Caribbean, under a wide variety of cropping systems. Besides its main use as dhal (dry, dehulled, split seed used for cooking), pigeonpea's tender green seeds are used as a vegetable, while crushed dry seeds serve as animal feed, green leaves as fodder, and stems as fuel wood and to make huts, baskets, etc. (Nene and Sheila 1990).

Exploration for genetic variability and diversity is very important for improving both the agronomic and nutritional traits of pigeonpea. The trypsin and chymotrypsin inhibitors are widely distributed among many plant families and are considered to be involved in regulating endogenous proteases and protecting plants against insect and pathogen attack, and also to function as storage proteins (Liener and Kakade 1980; Ryan 1990). Protease inhibitors have been studied extensively in several grain legume species. Examination of these inhibitors in soybean, the mostthoroughly studied of all legume species, showed that they are anti-nutritional and that their residual activities, even in processed human foods, are a cause of concern to human health (Gumbmann et al. 1986; Liener 1986; Brandon et al. 1991). Protease inhibitors in pigeonpea were also considered to be anti-nutritional factors that affected protein quality and can be reduced by cooking, germination, or fermentation (Singh and Eggum 1984; Singh 1988). Studies of protease inhibitors in pigeonpea and its wild relatives have so far been very limited (Singh and Jambunathan 1981; Mulimani and Paramjyothi 1992; Pichare and Kachole 1992). Furthermore, the effect of environmental conditions on the levels of these protease inhibitors in the seeds of any grain-legume species has not been previously reported.

In this study, we examine the genetic variation of trypsin and chymotrypsin inhibitors among various land races and cultivars of pigeonpea and its wild relatives in the genus Cajanus (previously classified in the genus Atylosia; Maesen 1990) as estimated by their electrophoretic band- 
ing patterns in non-denaturing polyacrylamide gels and by their inhibitor activities using spectrophotometry. The effect of environment on the levels of trypsin and chymotrypsin inhibitor activities was also studied by growing the selected strains of pigeonpea at various locations.

\section{Materials and methods}

\section{Plant material}

A total of 69 strains, including land races and cultivars, of pigeonpea (C. cajan) from India, East and West Africa, and the Caribbean, two accessions of $C$. cajanifolius (Haines) van der Maesen, ten accessions of $C$. scarabaeoides (L.) Thouars, and one accession each of C. acutifolius (F.v. Muell.) van der Maesen, C. albicans (W. \& A.) van der Maesen, C. lineatus (W. \& A.) van der Maesen, C. platycarpus (Benth.) van der Maesen, and C. volubilis (Blanco) Blanco, were obtained from the International Crops Research Institute for SemiArid Tropics (ICRISAT), Patancheru, India. Thirty of the sixty-nine pigeonpea strains were selected to study the effect of environment. Seeds of these strains were harvested from their area of adaptation in Tanzania and Kenya at 20-1500 meters above sea level (masl), considered as location I in this study, grown during November 1990 to August 1991 (Table 1). These seeds were then grown in the following season (November 1991-August 1992) at two different locations (environments): at Kibwezi in Kenya, $700 \mathrm{msal}, 2^{\circ} \mathrm{S}$ latitude (location II) and at Katumani in Kenya, $1600 \mathrm{msal}, 2^{\circ} \mathrm{S}$ latitude (location III). Lists of the strains of pigeonpea and its wild relatives with their identification number, source, and code number are given in Tables 1 and 2, respectively.

Polyacrylamide-gel electrophoresis (PAGE) and inhibitor activity staining

After removal of the seed coat, 2-5 seeds from each strain were crushed to a fine meal using flat-nosed pliers and 50-100-mg seed meal samples were placed in $1.5-\mathrm{ml}$ microcentrifuge tubes. Tris$\mathrm{CaCl}_{2} \mathrm{pH} 8.1$ buffer, containing $0.023 \mathrm{M} \mathrm{CaCl}_{2}$ and $0.092 \mathrm{M}$ Tris$\mathrm{HCl}$ [tris (hydroxymethyl) aminomethane, $\mathrm{pH}$ adjusted to 8.1 with $\mathrm{HCl}$, was used to extract the inhibitors. Final concentrations of the samples were precisely adjusted to $50 \mathrm{mg}$ of seed meal per $\mathrm{ml}$ of the buffer in the case of pigeonpea and $100 \mathrm{mg}$ of seed-meal per ml of the buffer in the case of the wild Cajanus species. The samples were incubated in the refrigerator $\left(4^{\circ} \mathrm{C}\right)$ overnight for protease-inhibitor extraction. The samples were thoroughly mixed 2-3 times during the extraction period using a vortex-mixer and the supernatant was clarified by centrifugation at $10000 \mathrm{~g}$ for $2-5 \mathrm{~min}$ at $4^{\circ} \mathrm{C}$. The supernatant from each sample was used for both the electrophoretic analysis and the spectrophotometric assays.

PAGE was based on the Laemmli (1970) method without SDS as described by Kollipara et al (1991). This gel system was primarily non-denaturing, discontinuous, and uniform. PAGE was conducted using a Mini-PROTEAN ${ }^{\circledR}$ II Cell from Bio-Rad Laboratories, Richmond, Calif.. All the solutions were filter-sterilized $(0.45 \mu \mathrm{m}$ nitrocellulose filters, Micron Separation Inc). In brief, the resolving gel consisted of $12 \%$ acrylamide:bis (30:0.8) and $0.375 \mathrm{M}$ Tris- $\mathrm{Cl}, \mathrm{pH}$ 8.8 , and the stacking gel consisted of $3.9 \%$ acrylamide:bis $(30: 0.8)$ and $0.125 \mathrm{M}$ Tris- $\mathrm{Cl}, \mathrm{pH} 6.8$. Both gels were polymerized by adding ammonium persulfate and TEMED $\left(\mathrm{N}, \mathrm{N}, \mathrm{N}^{\prime}, \mathrm{N}^{\prime}\right.$-tetramethylethylenediamine) to a final concentration of 0.05 and $0.1 \%$, respectively. The running buffer consisted of an $0.025 \mathrm{M}$ Tris base and $0.193 \mathrm{M}$ glycine ( $\mathrm{pH}$ not adjusted). All the gels were cast with the stacking gels about $1-1.5 \mathrm{~cm}$ high from the bottom of the wells to the top of the separating gels. A dye solution consisting of 20 or $60 \%$ glycerol with $0.005 \%$ bromophenol blue in distilled water was mixed with the seed extract in the ratio of $1: 1$ or 1:5, respectively, and an aliquot of 2-12.5 ml was applied to each sample well. The gels were run at a constant potential difference of $200 \mathrm{~V}$ until the bromophenol blue dye-front migrated to the end of the gel (approximately $45 \mathrm{~min}$ ).
At the end of electrophoresis, the stacking gels were removed and the separating gels were stained for $\mathrm{TI}$ and $\mathrm{Cl}$ activities based on Uriel and Berges (1968) with some modification (Kollipara and Hymowitz 1992). The gels were first washed in $0.1 \mathrm{M}$ sodium phosphate buffer $(\mathrm{pH} 7.5)$ in a glass tray on an orbital shaker for three 5 -min washes to equilibrate the gel with phosphate buffer. The gels were then incubated in phosphate buffer containing $15 \mathrm{mg} / \mathrm{ml}$ of bovine trypsin or $\alpha$-chymotrypsin for 15-20 min on the shaker at room temperature. At the end of the incubation period gels were rinsed three times for $2 \mathrm{~min}$ each rinse in distilled water before incubating in staining solution. The staining solution was prepared by dissolving $20 \mathrm{mg}$ of $\mathrm{N}$-acetyl-DL-phenylalanine $\beta$-naphthyl ester (APNE) in $8 \mathrm{ml}$ of $\mathrm{N}, \mathrm{N}$-dimethylformamide and $40 \mathrm{mg}$ of o-dianisidine, tetrazoitized (zinc chloride complex) in $80 \mathrm{ml}$ of distilled water separately. These solutions were mixed immediately before pouring on the gel. The gels were stained for 4-10 h without shaking in the dark. The stained gels were rinsed in distilled water and stored in $7 \%$ acetic acid.

\section{Spectrophotometric assays of protease inhibitors}

The TI and CI activity assays were conducted based on Hummel's (1959) method using p-toluenesulfonyl-L-arginine methyl ester (TAME) and N-benzoyl-L-tyrosine ethyl ester (BTEE), respectively, as substrates according to the procedure described by Kollipara and Hymowitz (1992). A trypsin or $\alpha$-chymotrypsin unit (TU or CU) is defined as the amount of trypsin or $\alpha$-chymotrypsin that catalyzes the hydrolysis of $1 \mu$ mole of the substrate (TAME and BTEE, respectively) per min. A trypsin or $\alpha$-chymotrypsin inhibitor unit (TIU or $\mathrm{CIU}$ ) is the reduction in the activities of the respective enzymes by one unit, i.e., TU and CU, respectively (Friedman et al. 1991).

\section{Results}

\section{The $\mathrm{TI}$ and $\mathrm{CI}$ banding patterns}

All pigeonpea strains contained several TI bands with highly-uniform migration patterns (Fig. 1). At least two high-intensity and three low-intensity bands with $\mathrm{Rf}$ values of 0.55-0.60 (band 5 and 6) and 0.30-0.50 (band 1,2, and 4), respectively, were observed across all the strains (Fig. 1). Three strains from West Africa (ICP 8194, ICP 13574, and ICP 13575) contained one additional faint band, each with an Rf value of about 0.45 (band 3 in Fig. 1). Variations in the TI band intensities were also observed among the pigeonpea strains. Some of the strains exhibited slower migrating bands (bands $1-4$ ) with extremelylow intensities and could only be observed in the gel (not obvious from the photograph, see Fig. 1). Accessions of all the wild Cajanus species contained TI bands (Fig. 2). A high degree of variation in the migration pattern, number, and intensities of the TI bands was observed among the wild species of the genus Cajanus. However, the migration patterns of these bands were uniform among the accessions within a species in the case of both of $C$. cajan ifolius and C. scarabaeoides (Fig. 2). The migration pattern of TIs in C. cajanifolius was strikingly similar to that in $C$. cajan. Cajanus lineatus and C. albicans also showed one major band each with a migration distance similar to that observed in $C$. cajan and $C$. cajanifolius.

The CI-activity staining revealed the presence of only a single band in pigeonpea as shown in Fig. 3. This band 


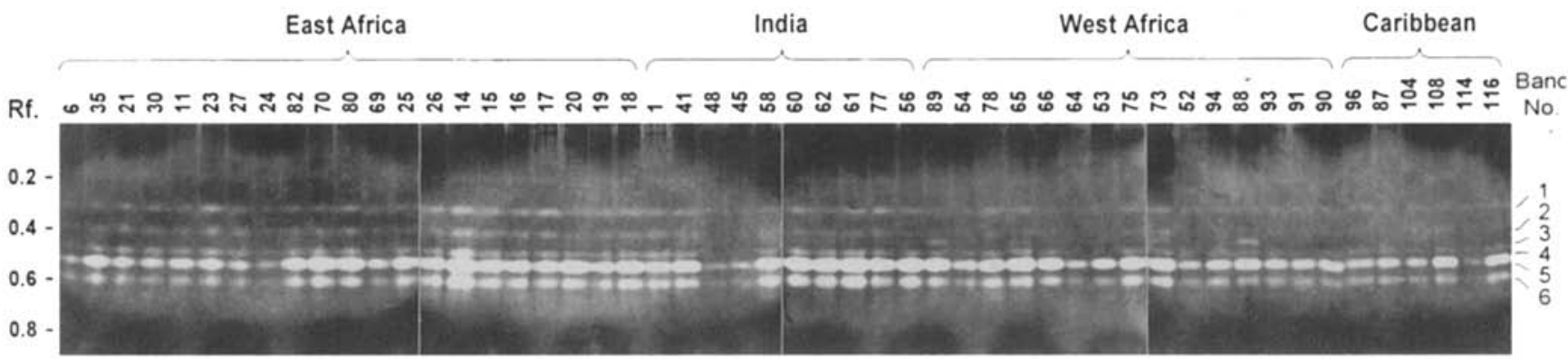

Fig. 1 Trypsin inhibitors in pigeonpea strains resolved by non-denaturing $12 \%$ PAGE and stained for TI activity. Crude extract from $125 \mu \mathrm{g}$ of seed-meal (i.e., $2.5 \mu \mathrm{l}$ of $50 \mathrm{mg} / \mathrm{ml}$ seed extract $+2.5 \mu \mathrm{l}$ of $20 \%$ dye solution) was applied per lane in each strain. The code

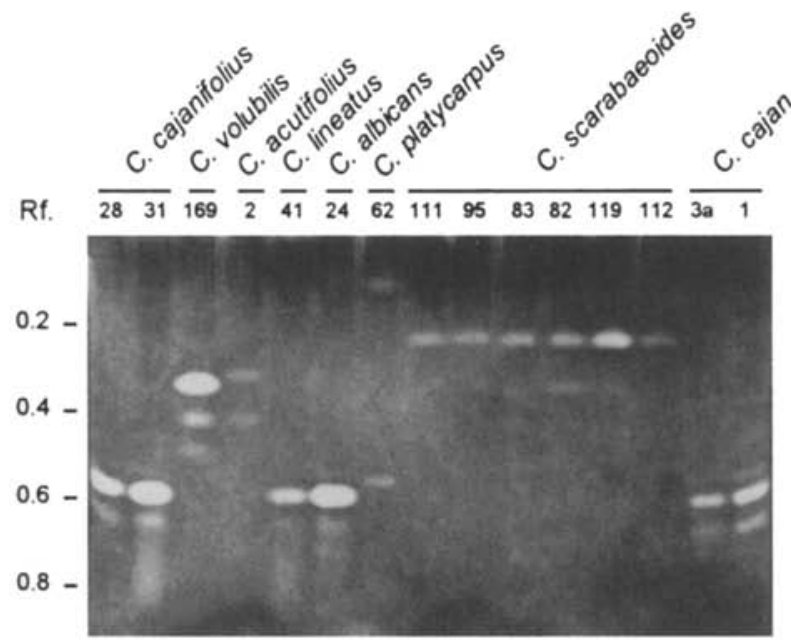

Fig. 2 Trypsin inhibitors in the wild Cajanus species resolved by non-denaturing $12 \%$ PAGE. Crude extract from $100 \mu \mathrm{g}$ of seed-meal (i.e., $1 \mu \mathrm{l}$ of $100 \mathrm{mg} / \mathrm{ml}$ of seed extract $+1 \mu \mathrm{l}$ of $20 \%$ dye solution) was applied per lane. Species names and accession numbers (ICPW numbers) are shown above the lanes (see Table 2). Cajanus cajan (pigeonpea) strains: $3 \mathrm{a}$ and 1 are same as $\operatorname{Tr} 3 \mathrm{a}$ and $\mathrm{T} 7$, respectively, as shown in Table 1 numbers of the strains (see Table 1) and their geographical distribution are shown above the corresponding lanes. The scale of band migration distance ( $\mathrm{Rf}$ scale) and the band numbers are indicated on either side of the gel

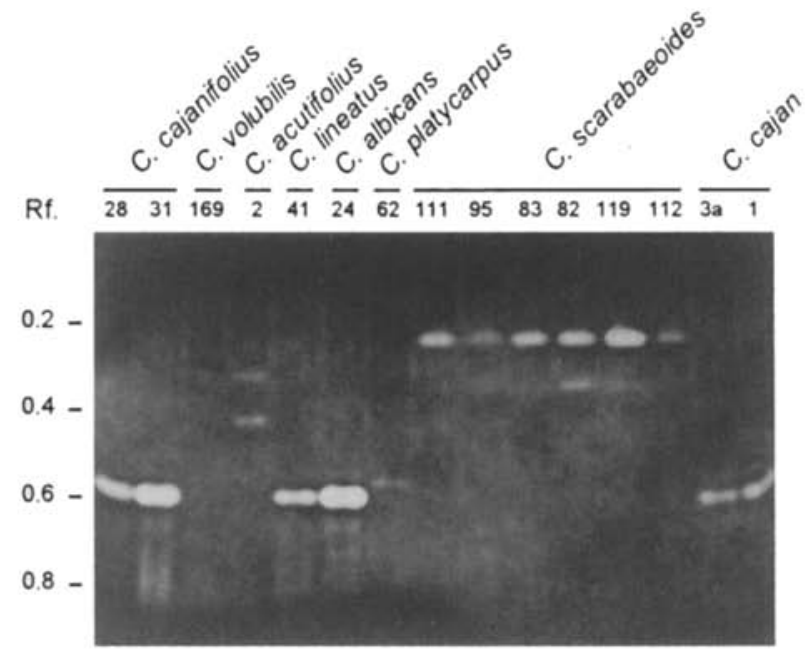

Fig. 4 Chymotrypsin inhibitors in the wild Cajanus species separated by non-denaturing $12 \%$ PAGE. Crude extract from $170 \mu \mathrm{g}$ of seed-meal (i.e., $1.7 \mu \mathrm{l}$ of $100 \mathrm{mg} / \mathrm{ml}$ seed extract $+0.3 \mu \mathrm{l}$ of $60 \%$ dye solution) was applied per lane. Species names and accession numbers (ICPW numbers) are shown above the lanes (see Table 2)

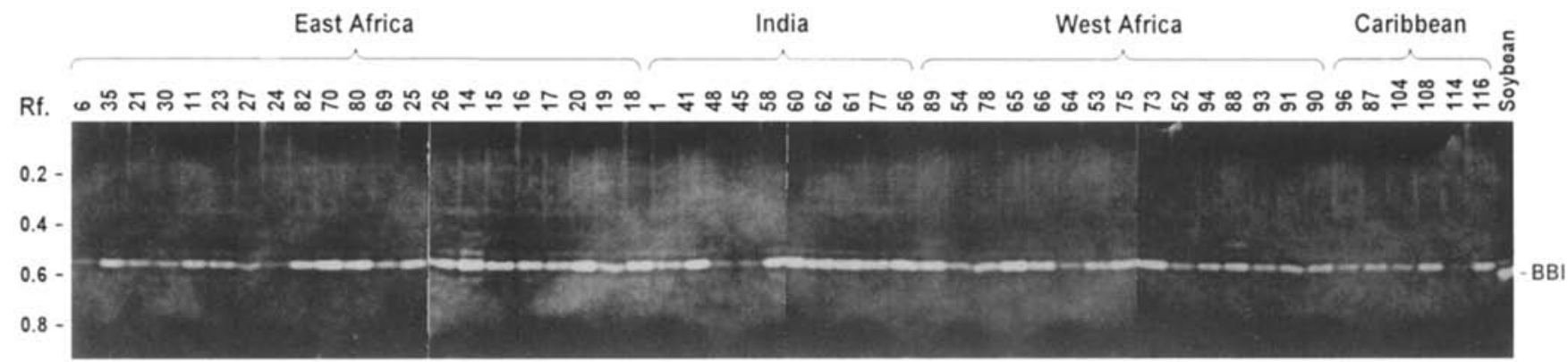

Fig. 3 Chymotrypsin inhibitors in pigeonpea strains separated by non-denaturing $12 \% \mathrm{PAGE}$ and stained for $\mathrm{CI}$ activity. Crude extract from $250 \mu \mathrm{g}$ of seed-meal (i.e., $5 \mu \mathrm{l}$ of $50 \mathrm{mg} / \mathrm{ml}$ seed extract $+5 \mu \mathrm{l}$ of $20 \%$ dye solution) was applied per lane in each strain. The code numbers of the strains (see Table 1) and their geographical distribution are shown above the corresponding lanes. The $\mathrm{Rf}$ scale is indicated on left and the soybean BBI (Bowman-Birk Inhibitor) is shown on the right side of the gel was observed in all pigeonpea strains with the same Rf value but with varying intensities and was identified to be the same as one of the major TI bands in pigeonpea (band 5 in Fig. 1). Similar observations were recorded in the wild species where the CI bands were same as the major TI bands in most of the species (Figs. 2 and 4). Caja- nus volubilis accession (ICPW 169) used in this study was found to be "null" for CIs. When an excess amount of sample was loaded per lane, $C$. volubilis still did not exhibit $\mathrm{CI}$ bands but several new bands were resolved in the other species (Fig. 5). Some new bands were highly diffused and the others showed a weaker reaction (lower intensity). 


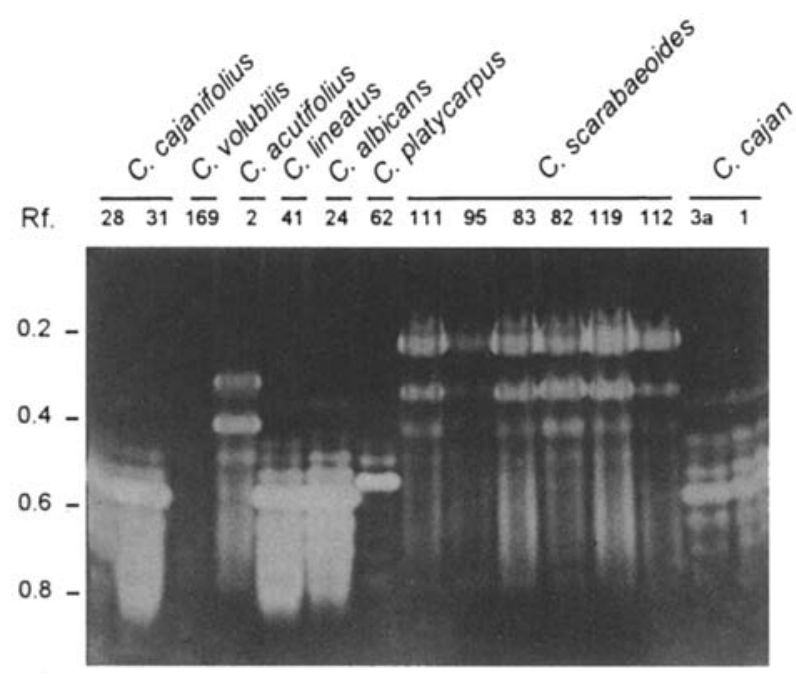

Fig. 5 The profiles of chymotrypsin inhibitors when excess amounts of samples, i.e., crude extract from $1040 \mu \mathrm{g}$ of seed-meal $(10.4 \mu \mathrm{l}$ of $100 \mathrm{mg} / \mathrm{ml}$ seed extract $+2.1 \mu \mathrm{l}$ of $60 \%$ dye solution), was loaded in each well of a $12 \%$ non-denaturing gel. The corresponding samples in each lane are identified above and the Rf scale is given on the left side of the gel

\section{The TI and CI activities}

Highly-significant variation was observed in the TIU/g seed values among the pigeonpea strains (Table 1). The TIU/g seed values ranged from $1222 \pm 111.1$ units in the strain Kenya 2 to $3722 \pm 55.6$ units in the strain ICPW 9151. No specific pattern was observed in the TI activities among the pigeonpea strains based on their geographical distribution. Significant variations in TIU/g seed values were also observed among the wild Cajanus species. Accessions of C. albicans, C. cajanifolius, and C. volubilis showed higher TI activities (TIU/g seed) compared to those in the accessions of C. acutifolius, C. platycarpus, and C. scarabaeoides (Table 2). Cajanus platycarpus accession (ICPW 62) contained the lowest TI activity ( $383 \pm 12.4 \mathrm{TIU} / \mathrm{g}$ seed) of all the pigeonpea and the wild Cajanus species strains used in this study. The mean TIU/g seed value of the wild species (1407 \pm 119.8 units) was also much lower than that of the pigeonpea strains ( $2279 \pm 49.9$ units; Tables 1 and 2 ). In general, the TIU/g seed values of pigeonpea and its wild relatives corroborated well with the band intensities observed in the gels stained for TI activities (Tables 1-2; Figs. $1-5)$.

The CI activity (CIU/g seed) was also found to be significantly variable among pigeonpea strains, ranging from $31 \pm 0.0$ units in Kenya 2 to $87 \pm 0.0$ units in ICP 9151 (Table 1). The accessions of wild Cajanus species exhibited an even higher degree of variation in their CI activities (Table 2). As expected, C. volubilis accession (ICPW 169) did not contain any detectable CI activity, confirming the lack of CIs observed in the activity-stained gels (Figs. 4 and 5). The mean CIU/g seed value of wild Cajanus species $(162 \pm 12.8$ units) was significantly higher than that of the pigeonpea strains ( $62 \pm 1.0$ units; Tables 1 and 2$)$. The CIU/g seed values in both pigeonpea and its wild relatives (ex- cept $C$. volubilis) also correlated positively with the TIU/g seed values (Table 1 and 2).

Effect of environment on the protease inhibitor activities

Environment, strain, and environment $\times$ strain interaction all showed statistically significant effects on the TI and CI activities (data not shown). The mean values of all the seed traits measured, such as 100 seed weight, seed-protein content, TIU/g seed, TIU/g protein, CIU/g seed, and CIU/g protein, in the 30 selected pigeonpea strains are given in Table 3. The seed weight was observed to have increased when the pigeonpea strains were grown at the higher altitude (location III, at 1600 masl). The mean TIU/g seed, $\mathrm{TIU} / \mathrm{g}$ protein, CIU/g seed, and CIU/g protein values were highest when the pigeonpea was grown at 700 masl, followed by those at 1600 masl. These values were lowest in the pigeonpea strains grown at the area of their adaptation (Table 3).

The correlation coefficients between various traits measured across the 30 pigeonpea strains are shown in Table 4. Statistically-significant positive correlations were observed among TIU/g seed, TIU/g protein, CIU/g seed, and $\mathrm{CIU} / \mathrm{g}$ protein values. However, significantly-negative correlations were observed between seed weight and protein content and also between the protein content and $\mathrm{ClU} / \mathrm{g}$ protein. The seed weights were not found to be correlated significantly with the TI and CI activities (Table 4).

\section{Discussion}

Highly-uniform banding patterns of TIs and CIs among the pigeonpea strains suggest that these proteins are strongly conserved (Figs. 1 and 3). The conservative nature of these proteins has made them very useful markers to study the biosystematics of several plant species, including those of Glycine (Weder 1985; Kollipara et al. 1993). This is also evident from the migration patterns of these proteins in the wild Cajanus species. In the wild species, these inhibitors exhibited highly species specific banding patterns with a fair amount of uniformity among the accessions within a species, as observed in case of C. cajanifolius and C. scarabaeoides (Figs. 2, 4, and 5). The migration patterns of the two major inhibitors in C. cajanifolius were similar to those observed in $C$. cajan (pigeonpea), suggesting that $C$. $c a$ janifolius is genomically closest to the pigeonpea. This observation agrees with the previously reported cyto-morphological, isozyme, and molecular evidence (Krishna and Reddy 1982; Pundir and Singh 1985; Nadimpalli et al. 1993). We found that the major TI and CI band in both $C$. lineatus and $C$. albicans accessions co-migrated with that in $C$. cajan, indicating a closer genomic relationship among these species (Figs. 2, 4, and 5). Based on cytological and electrophoretic analyses, Pundir and Singh (1985) also found that $C$. cajan was closer to $C$. lineatus followed by C. cajanifolius. 
Table 1 List of the pigeonpea strains with the mean values of trypsin inhibitor units (TIU) and chymotrypsin inhibitor units (CIU) per gram seed from two estimations by spectrophotometric activity-assays

\begin{tabular}{|c|c|c|c|c|}
\hline $\begin{array}{l}\text { Code } \\
\text { no. }^{a}\end{array}$ & $\begin{array}{l}\text { Strain } \\
\text { identification }^{b}\end{array}$ & Source $^{c}$ & $\begin{array}{l}\mathrm{TIU} / \mathrm{g} \\
\text { seed } \pm \mathrm{SE}\end{array}$ & $\begin{array}{l}\mathrm{CIU} / \mathrm{g} \\
\text { seed } \pm \mathrm{SE}\end{array}$ \\
\hline $1 *$ & $\mathrm{~T} 7$ & India Land race Selection & $2222 \pm 222.2$ & $56 \pm 0.0$ \\
\hline $2 *$ & ICPL 91055 & ICRISAT Pigeonpea Breeding & $1722 \pm 55.6$ & $56 \pm 6.2$ \\
\hline $3^{*}$ & ICPL 91056 & ICRISAT Pigeonpea Breeding & $1778 \pm 444.5$ & $53 \pm 3.1$ \\
\hline $4^{*}$ & ICPL 91058 & ICRISAT Pigeonpea Breeding & $2500 \pm 167.0$ & $68 \pm 6.2$ \\
\hline $5^{*}$ & 1 Babati & Tanzania (EA) LS Col. 1210 masl & $3333 \pm 333.5$ & $78 \pm 3.1$ \\
\hline $6 *$ & 4 Babati & Tanzania (EA) LS Col. 1440 masl & $1667 \pm 222.2$ & $40 \pm 3.1$ \\
\hline $7 *$ & 4 ILCA & GRU ILCA & $2444 \pm 333.5$ & $59 \pm 3.1$ \\
\hline $8 *$ & Kat. 777 & Kenya (EA) Katumani Selection & $2889 \pm 333.0$ & $72 \pm 3.1$ \\
\hline $9 *$ & Kat. 2 & Kenya (EA) Katumani Selection & $2889 \pm 111.1$ & $75 \pm 0.0$ \\
\hline $10^{*}$ & Kat. $81 / 3 / 3$ & Kenya (EA) Katumani Selection & $2556 \pm 777.5$ & $75 \pm 6.2$ \\
\hline $11^{*}$ & Kenya 12 & Kenya (EA) LS Col. 1530 masl & $2388 \pm 55.6$ & $59 \pm 3.1$ \\
\hline $12 *$ & Kenya 17 & Kenya (EA) LS Col, Market Sample & $3222 \pm 111.1$ & $75 \pm 0.0$ \\
\hline $13 *$ & Kenya 18 & Kenya (EA) LS Col. Market Sample & $2167 \pm 166.5$ & $56 \pm 0.0$ \\
\hline $14^{*}$ & Tanzania 2 & Tanzania (EA) LS Col. 590 masl & $2500 \pm 166.7$ & $65 \pm 3.1$ \\
\hline $15^{*}$ & Tanzania 6 & Tanzania (EA) LS Col. 270 masl & $1611 \pm 55.6$ & $53 \pm 3.1$ \\
\hline $16^{*}$ & Tanzania 10 & Tanzania (EA) LS Col. 330 masl & $1888 \pm 111.1$ & $65 \pm 3.1$ \\
\hline $17^{*}$ & Tanzania 18 & Tanzania (EA) LS Col. 340 masl & $1722 \pm 55.6$ & $56 \pm 0.0$ \\
\hline $18 *$ & Tanzania 20 & Tanzania (EA) LS Col. 120 masl & $2111 \pm \quad 0.0$ & $65 \pm 3.1$ \\
\hline $19^{*}$ & Tanzania 21 & Tanzania (EA) LS Col. 20 masl & $2167 \pm 166.7$ & $65 \pm 3.1$ \\
\hline $20^{*}$ & Tanzania 22 & Tanzania (EA) LS Col. 20 masl & $2444 \pm 111.1$ & $81 \pm 6.2$ \\
\hline $21 *$ & 7 Babati 12 & Tanzania (EA) LS Col. 30 masI & $1944 \pm 166.7$ & $50 \pm 0.0$ \\
\hline $22 *$ & Tanzania 12 & Tanzania (EA) LS Col. 340 masl & $1389 \pm 278.0$ & $50 \pm 0.0$ \\
\hline $23 *$ & Kenya 1 & Kenya (EA) LS Col. 1100 masl & $1944 \pm 55.6$ & $50 \pm 0.0$ \\
\hline $24 *$ & Kenya 2 & Kenya (EA) LS Col. 1120 masl & $1222 \pm 111.1$ & $31 \pm 0.0$ \\
\hline 25 & Kenya 7 & Kenya (EA) LS Col. 680 masl & $2500 \pm 388.9$ & $75 \pm 6.2$ \\
\hline 26 & Kenya 4 & Kenya (EA) LS Col. 850 masl & $2222 \pm 333.3$ & $65 \pm 3.1$ \\
\hline 27 & Kenya 20 & Kenya (EA) LS Col. Market sample & $1778 \pm 111.1$ & $44 \pm 0.0$ \\
\hline $28 *$ & Gwalior 3 & India Land race Selection & $2111 \pm 222.2$ & $53 \pm 3.1$ \\
\hline $29 *$ & ICPL 366 & ICRISAT Pigeonpea Breeding & $2722 \pm 389.0$ & $68 \pm 6.2$ \\
\hline 30 & 9 Babati & Tanzania (EA) LS Col. 1400 masl & $1611 \pm 55.6$ & $37 \pm 0.0$ \\
\hline $31 *$ & 16 Babati & Tanzania (EA) LS Col. 1400 masl & $3277 \pm 55.6$ & $68 \pm 6.2$ \\
\hline $34 *$ & ICP 11820 & GRU ICRISAT & $1945 \pm 276.5$ & $56 \pm 0.0$ \\
\hline 35 & 12 Babati & Tanzania (EA) LS Col. 1400 masl & $3111 \pm 222.2$ & $72 \pm 3.1$ \\
\hline $36^{*}$ & Tanzania 23 & Tanzania (EA) LS Col. 460 masl & $2333 \pm 111.1$ & $72 \pm 3.1$ \\
\hline 41 & ICPL $87 \mathrm{~B}$ & ICRISAT Pigeonpea Breeding & $2444 \pm 222.2$ & $65 \pm 3.1$ \\
\hline $42 *$ & 2 ILCA & GRU ILCA & $3389 \pm 389.0$ & $81 \pm 6.2$ \\
\hline 45 & Dwarf 21 & ICRISAT Pigeonpea Breeding & $1500 \pm 55.6$ & $47 \pm 3.1$ \\
\hline 48 & Dwarf 4 & ICRISAT Pigeonpea Breeding & $1611 \pm 55.6$ & $53 \pm 3.1$ \\
\hline 52 & ICP 2811 & Nigeria (WA) GRU ICRISAT & $2167 \pm 55.6$ & $56 \pm 3.1$ \\
\hline 53 & ICP 4024 & Nigeria (WA) GRU ICRISAT & $1556 \pm 333.3$ & $47 \pm 0.0$ \\
\hline 54 & ICP 4715 & Ghana (WA) GRU ICRISAT & $1722 \pm 55.6$ & $47 \pm 3.1$ \\
\hline 56 & ICP 6997 & India GRU ICRISAT & $2556 \pm 222.2$ & $62 \pm 0.0$ \\
\hline 58 & ICP 7035 & India GRU ICRISAT & $2000 \pm 111.1$ & $56 \pm 0.0$ \\
\hline 60 & ICP 8006 & India GRU ICRISAT & $2278 \pm 55.6$ & $65 \pm 3.1$ \\
\hline 61 & ICP 8081 & India GRU ICRISAT & $2278 \pm 55.6$ & $62 \pm 0.0$ \\
\hline 62 & ICP 8084 & India GRU ICRISAT & $2000 \pm 111.1$ & $62 \pm 6.2$ \\
\hline 64 & ICP 8193 & Senegal (WA) GRU ICRISAT & $2222 \pm 111.1$ & $65 \pm 3.1$ \\
\hline 65 & ICP 8194 & Senegal (WA) GRU ICRISAT & $2611 \pm 55.6$ & $75 \pm 0.0$ \\
\hline 66 & ICP 8202 & Senegal (WA) GRU ICRISAT & $2167 \pm 166.7$ & $62 \pm 0.0$ \\
\hline 69 & ICP 9150 & Kenya (EA) GRU ICRISAT & $3111 \pm 111.1$ & $75 \pm 0.0$ \\
\hline 70 & ICP 9151 & Kenya (EA) GRU ICRISAT & $3722 \pm 55.6$ & $87 \pm 0.0$ \\
\hline 73 & ICP 9272 & Nigeria (WA) GRU ICRISAT & $2111 \pm 0.0$ & $65 \pm 3.1$ \\
\hline 75 & ICP 11479 & Nigeria (WA) GRU ICRISAT & $2000 \pm 333.3$ & $72 \pm 3.1$ \\
\hline 77 & ICP 11934 & India GRU ICRISAT & $1889 \pm 111.1$ & $59 \pm 3.1$ \\
\hline 78 & ICP 12190 & Ghana (WA) GRU ICRISAT & $2389 \pm 55.6$ & $65 \pm 3.1$ \\
\hline 80 & ICP 13075 & Kenya (EA) GRU ICRISAT & $3444 \pm 111.1$ & $81 \pm 0.0$ \\
\hline 82 & ICP 13082 & Kenya (EA) GRU ICRISAT & $3000 \pm 0.0$ & $72 \pm 3.1$ \\
\hline 87 & ICP 13556 & Grenada (WI) GRU ICRISAT & $2278 \pm 277.8$ & $50 \pm 6.2$ \\
\hline 88 & ICP 13574 & Sierra Leone (WA) GRU ICRISAT & $2444 \pm 333.3$ & $75 \pm 0.0$ \\
\hline 89 & ICP 13575 & Sierra Leone (WA) GRU ICRISAT & $3167 \pm 277.8$ & $78 \pm 3.1$ \\
\hline 90 & ICP 13576 & Sierra Leone (WA) GRU ICRISAT & $1889 \pm 111.1$ & $59 \pm 3.1$ \\
\hline 91 & ICP 13640 & Cape Verde (WA) GRU ICRISAT & $2056 \pm 55.6$ & $59 \pm 3.1$ \\
\hline 93 & ICP 13642 & Cape Verde (WA) GRU ICRISAT & $1889 \pm 111.1$ & $65 \pm 3.1$ \\
\hline 94 & ICP 13643 & Cape Verde (WA) GRU ICRISAT & $2000 \pm 111.1$ & $62 \pm 6.2$ \\
\hline 96 & ICP 13820 & Grenada (WI) GRU ICRISAT & $2500 \pm 55.6$ & $56 \pm 0.0$ \\
\hline
\end{tabular}


Table 1 (continued)

\begin{tabular}{|c|c|c|c|c|}
\hline $\begin{array}{l}\text { Code } \\
\text { no. }{ }^{a}\end{array}$ & $\begin{array}{l}\text { Strain } \\
\text { identification }^{b}\end{array}$ & Source $^{c}$ & $\begin{array}{l}\mathrm{TIU} / \mathrm{g} \\
\text { seed } \pm \mathrm{SE}\end{array}$ & $\begin{array}{l}\mathrm{CIU} / \mathrm{g} \\
\mathrm{seed} \pm \mathrm{SE}\end{array}$ \\
\hline $\begin{array}{l}104 \\
108 \\
114 \\
116\end{array}$ & $\begin{array}{l}\text { ICP } 13856 \\
\text { ICP } 13860 \\
\operatorname{Tr} 3 \mathrm{a} \\
\operatorname{Tr} 3 \mathrm{c}\end{array}$ & $\begin{array}{l}\text { St.Vincent (WI) GRU ICRISAT } \\
\text { St.Vincent (WI) GRU ICRISAT } \\
\text { Trinidad (WI) LS Col. } \\
\text { Trinidad (WI) LS Col. }\end{array}$ & $\begin{array}{ll}2 & 167 \pm 277.8 \\
2 & 222 \pm 0.0 \\
1 & 444 \pm 111.1 \\
2 & 667 \pm 111.1\end{array}$ & $\begin{array}{l}62 \pm 12.5 \\
56 \pm 6.2 \\
37 \pm 6.2 \\
56 \pm 0.0\end{array}$ \\
\hline $\begin{array}{l}\text { Mean } \\
\text { SE } \pm \\
\text { CV\% }\end{array}$ & & & $\begin{array}{r}2279 \\
49.9 \\
13.2\end{array}$ & $\begin{array}{l}62 \\
1.0 \\
8.6\end{array}$ \\
\hline
\end{tabular}

a Temporary numbers assigned at the University of Illinois, * strains selected to study the effect of environment

b Identification numbers designated by International Crops Research Center for Semi-Arid Tropics (ICRISAT)

c EA, East Africa; GRU, Genetic Resource Unit; ILCA, International Livestock Center for Africa; LS Col., collected by Laxman Singh; masl, meters above sea level; WA, West Africa; WI, West Indies

Table 2 Wild relatives of pigeonpea (C. cajan), accession number, and mean values of trypsin inhibitor units (TIU) and chymotrypsin inhibitor units (CIU) per gram seed from three estimations by spectrophotometric activity-assays

\begin{tabular}{llrr}
\hline Species & $\begin{array}{l}\text { Accession } \\
\text { number }\end{array}$ & $\begin{array}{l}\text { TIU/g } \\
\text { seed } \pm \text { SE }\end{array}$ & $\begin{array}{l}\text { CIU/g } \\
\text { seed } \pm \text { SE }\end{array}$ \\
\hline C. acutifolius (F.v. Muell.) van der Maesen & ICPW 2 & $741 \pm 14.8$ & $91 \pm 4.2$ \\
C. albicans (W. \& A.) van der Maesen & ICPW 24 & $2852 \pm 98.0$ & $398 \pm 25.0$ \\
C. cajanifolius (Haines) van der Maesen & ICPW 28 & $2333 \pm 111.1$ & $124 \pm 0.0$ \\
& ICPW 31 & $3370 \pm 225.3$ & $282 \pm 22.0$ \\
C. lineatus (W. \& A.) van der Maesen & ICPW 41 & $1481 \pm 196.0$ & $216 \pm 41.5$ \\
C. platycarpus (Benth.) van der Maesen & ICPW 62 & $383 \pm 12.4$ & $46 \pm 4.2$ \\
C. scarabaeoides (L.) Thouars & ICPW 82 & $1086 \pm 98.8$ & $167 \pm 15.0$ \\
& ICPW 83 & $1062 \pm 65.3$ & $145 \pm 11.0$ \\
& ICPW 87 & $1185 \pm 154.2$ & $162 \pm 26.0$ \\
& ICPW 95 & $913 \pm 24.7$ & $50 \pm 0.0$ \\
& ICPW 101 & $667 \pm 113.2$ & $162 \pm 36.0$ \\
& ICPW 111 & $889 \pm 0.0$ & $124 \pm 0.0$ \\
& ICPW 112 & $790 \pm 24.7$ & $100 \pm 0.0$ \\
& ICPW 117 & $963 \pm 42.8$ & $158 \pm 11.0$ \\
ICPW 119 & $1383 \pm 65.3$ & $199 \pm 7.2$ \\
C. volubilis (Blanco) Blanco & ICPW 122 & $1160 \pm 49.4$ & $166 \pm 4.2$ \\
\hline Mean & ICPW 169 & $2667 \pm 64.2$ & $0 \pm 0.0^{\mathrm{b}}$ \\
SE \pm & & 1407 & 162 \\
CV\% & & 119.8 & 12.8 \\
\hline
\end{tabular}

a Accession numbers are assigned by ICRISAT

${ }^{b} \mathrm{CIU} / \mathrm{g}$ seed value is excluded from the estimation of the mean, $\mathrm{SE}$, and $\mathrm{CV}$

Table 3 Mean, standard error (SE), and coefficient of variability (CV) of 100 seed weight, total seed protein ${ }^{\mathrm{a}}$, and the trypsin and chymotrypsin inhibitor units (TIU and CIU, respectively) of the selected 30 pigeonpea strains grown at three locations (environments)

\begin{tabular}{|c|c|c|c|c|c|c|c|c|c|}
\hline \multirow{3}{*}{$\begin{array}{l}\text { Parameters (traits) } \\
\text { measured }\end{array}$} & \multicolumn{9}{|c|}{ Location (environment) $^{\mathrm{b}}$} \\
\hline & \multicolumn{3}{|c|}{ (I) Area of adaptation } & \multicolumn{3}{|c|}{ (II) 700 masl } & \multicolumn{3}{|c|}{ (III) 1600 masI } \\
\hline & Mean & $\mathrm{SE}$ & $\mathrm{CV}(\%)$ & Mean & SE & $\mathrm{CV}(\%)$ & Mean & SE & $\mathrm{CV}(\%)$ \\
\hline 100 seed wt. (g) & 14.0 & \pm 0.42 & 4.3 & 13.5 & \pm 0.43 & 6.1 & 15.7 & $\pm \quad 0.44$ & 7.9 \\
\hline Total protein $(\%)$ & 22.5 & \pm 0.43 & 3.1 & 22.2 & \pm 0.21 & 2.4 & 22.6 & $\pm \quad 0.19$ & 1.6 \\
\hline TIU/g seed & 2211 & \pm 98.4 & 19.9 & 2909 & \pm 101.3 & 14.4 & 2531 & \pm 129.7 & 22.1 \\
\hline TIU/g protein & 9846 & \pm 443.7 & 19.6 & 13133 & \pm 451.8 & 14.4 & 11205 & \pm 568.6 & 23.1 \\
\hline CIU/g seed & 60 & \pm 1.6 & 12.5 & 71 & \pm 1.2 & 7.6 & 65 & $\pm \quad 1.9$ & 8.5 \\
\hline $\mathrm{CIU} / \mathrm{g}$ protein & 269 & \pm 7.3 & 13.1 & 322 & $\pm \quad 5.8$ & 7.8 & 290 & \pm 8.6 & 8.3 \\
\hline
\end{tabular}

a Total protein was estimated using the micro-Kjeldahl method as described by Mulvaney (1993)

b Plants grown in three locations: (I), at the area of adaptation (see Table 1); (II), at Kibwezi, Kenya, at $700 \mathrm{~m}$ above sea level (masl); and (III), at Katumani, Kenya, at 1600 masl 
Table 4 Correlation coefficients among various seed quality parameters measured in 30 selected pigeonpea strains grown in three different environments

\begin{tabular}{lccccc}
\hline Parameter & \% Protein & TIUS $^{\mathrm{a}}$ & TIUP $^{\mathrm{b}}$ & CIUS $^{\mathrm{c}}$ & CIUP $^{\mathrm{d}}$ \\
\hline 100 seed wt. & $-0.28^{*}$ & 0.00 & 0.05 & 0.00 & 0.09 \\
\% Protein & & 0.07 & -0.13 & 0.03 & $-0.31^{*}$ \\
TIUS & & & $0.98^{*}$ & $0.82^{*}$ & $0.75^{*}$ \\
TIUP & & & & $0.81^{*}$ & $0.81^{*}$ \\
CIUS & & & & & $0.93^{*}$
\end{tabular}

a TIUS, trypsin inhibitor units/g seed

b TIUP, trypsin inhibitor units/g protein

c CIUS, chymotrypsin inhibitor units/g seed

d CIUP, chymotrypsin inhibitor units/g protein

* Correlation coefficients are significant at $\alpha=0.05$ level

The variation in $\mathrm{TI}$ and $\mathrm{CI}$ band intensities may simply be quantitative or could be the result of a weaker inhibition due to lower affinity of these inhibitors to the substrate (trypsin or chymotrypsin). Similar observations were previously recorded in soybean and its wild perennial relatives by Kollipara and Hymowitz (1992). The quantitative variations in the TI and $\mathrm{CI}$ activities found among the pigeonpea strains corroborated fairly well with the intensity variations of the respective inhibitor activity bands in the gels (Table 1,2; Figs. 1-5). A maximum of six TI bands (of which only two were prominent), but only one CI band, was observed among pigeonpea strains (Figs. 1 and 3). Multiple TI bands were also recorded by Pichare and Kachole (1992) upon subjecting the crude extracts of pigeonpea seed to isoelectric focussing. Up to six CI bands were seen when excess quantities of samples were analyzed per lane in the gel (Fig. 5). This was most likely due to a weaker and non-specific binding of these proteins (which appear to be TIs from their migration distances) to chymotrypsin. Such a weaker reaction was also observed in the case of the soybean Kunitz trypsin inhibitor (KTI), a specific inhibitor of trypsin (Kollipara 1992). The diffused and fastermigrating bands in some of the lanes might be due to specific and non-specific proteolytic degradation of the inhibitors. Specific proteolytic degradation of the KTI and the Bowman-Birk inhibitor (BBI), producing derivatives with inhibitor activities, was previously recorded in soybean (Madden et al. 1985; Wilson et al. 1988).

The TIU/g seed was at least two orders of magnitude higher than the CIU/g seed in pigeonpea (Table 1). These results conflict with the observations of Mulimani and Paramjyothi (1992) who found that CI activity was higher than TI activity in several pigeonpea strains. Furthermore, the TI and CI values reported by Singh and Jambunathan (1981) and Mulimani and Paramjoythi (1992) were much lower than those observed in the present study. One of the reasons for this may be because of the difference in the inhibitor extraction procedure. These previous authors presoaked the seeds in distilled water for over $12 \mathrm{~h}$ and only then were the seeds used for extracting the inhibitors. This could cause a partial loss of the inhibitors due to leaching. Significant portions of the protease inhibitors (Kunitz type and Bowman-Birk type) were shown to be localized in the extracellular spaces in soybean seed (Horishberger and Tacchini-Vonlanthen $1983 \mathrm{a}, \mathrm{b}$ ) and are released (by leaching) within a few hours after imbibition (Hwang et al. 1978; Tan-Wilson and Wilson 1982). Another reason for the disagreement in the inhibitor activity values could be due to the difference in defining the unit-enzyme (trypsin or chymotrypsin) and unit-inhibitor activities.

In order to improve the nutritional quality of pigeonpea for both human and animal consumption, the levels of these protease inhibitors must be reduced. Heat-processing (cooking by moist heat or microwave) of the seeds was shown to help denature most of these proteins in soybeans (Sakla et al. 1988; DiPietro and Liener 1989). However, it is also possible to eliminate or reduce these inhibitors by transferring the null or low-expressing alleles of these inhibitors (natural variants) to the cultivated strains through breeding. A good example of such an effort was the release of soybean cultivar 'Kunitz', an isoline of cv Williams 82 lacking the functional $T i$ allele (i.e., containing ti allele), which was shown to be nutritionally superior to $\mathrm{cv}$ Williams 82 in animal feeding studies (Bernard et al. 1991; Friedman et al. 1991; Han et al. 1991; Zhang et al. 1991). Pigeonpea strains with the lowest TI and CI activities identified in the present study, such as Kenya 2, Tr 3a, etc., could potentially be used in a breeding program to reduce the inhibitor contents of pigeonpea cultivars (Table 1). On the other hand, protease inhibitors are also considered to improve the plants defense against insect and pathogen attack (Ryan 1990). The high TI and CI strain, ICP 9151, identified in our study, could be used for breeding new cultivars that contain high levels of these inhibitors.

The TI and CI activities of pigeonpea strains increased when they were grown in environments (locations II and III) different from their area of adaptation (location I; Table 3). Highest activities were found when pigeonpea was grown at a lower altitude ( 700 masl). The mean maximum temperature was recorded to be about $3^{\circ} \mathrm{C}$ lower in high altitude (location III, 1600 masl) compared to that at low altitude (location II, 700 masl). The maturity periods were also altered due to the change in environment. All the 30 pigeonpea strains were of the long-duration type (210 days from planting to flowering) when they were grown in their area of adaptation (location I). When grown in a different environment (location II or III) most of the strains flowered earlier showing a medium- or short-duration type of behaviour (100-150 days from planting to flowering; data not shown). Therefore, the highly significant effect of environment on the TI and CI activities observed in this study might, in part, be due to the change in temperature and maturity period.

As expected from the band-intensity comparisons, highly-significant positive correlations were observed between the TI and CI activities (Figs. 1-5; Table 4). This could be due (as in soybean) to the presence of BowmanBirk type inhibitors which inhibit both trypsin and chymotrypsin simultaneously (Odani and Ikenaka 1973; Birk 1985). In the present study, we have, for the first time, identified the presence of such Bowman-Birk type inhibitors in pigeonpea and its wild relatives. However, further char- 
acterization needs to be done through purification and protein sequencing to gain a better understanding of these inhibitors.

Acknowledgements The authors would like to thank Dr. R. L. Mulvaney for providing facilities to perform the micro-Kjeldahl procedure. One of the authors, Laxman Singh, was supported by ICRISAT during the course of this investigation on his sabbatical leave.

\section{References}

Bernard RL, Hymowitz T, Cremeens CR (1991) Registration of 'Kunitz' soybean. Crop Sci 31:232-233

Birk Y (1985) The Bowman-Birk inhibitor: trypsin- and chymotrypsin-inhibitors from soybeans. Int J Peptide Protein Res 25: $113-131$

Brandon DL, Bates AH, Friedman M (1991) ELISA analysis of soybean trypsin inhibitors in processed foods. In: Friedman $M$ (ed) Nutritional and toxicological consequences of food processing. Plenum Press, New York, pp 321-337

DiPietro CM, Liener IE (1989) Heat inactivation of the Kunitz and Bowman-Birk soybean protease inhibitors. J Agric Food Chem $37: 39-44$

Friedman M, Brandon DL, Bates AH, Hymowitz T (1991) Comparison of a commercial soybean and an isoline lacking the Kunitz trypsin inhibitor: composition, nutritional value, and effects of heating. J Agric Food Chem 39:327-335

Gumbmann MR, Spangler WL, Dugan GM, Rackis JJ (1986) Safety of trypsin inhibitors in the diet: effects on the rat pancreas of long-term feeding of soy flour and soy protein isolate. In: Friedman $M$ (ed) Nutritional and toxicological significance of enzyme inhibitors in foods. Plenum Press, New York, pp 33-79

Han Y, Parsons CM, Hymowitz T (1991) Nutritional evaluation of soybeans varying in trypsin inhibitor content. Poultry Sci 70:896-906

Horishberger M, Tacchini-Vonlanthen M (1983a) Ultrastructural localization of Kunitz trypsin inhibitor on thin sections of Glycine $\max$ (soybean) cv Maple Arrow by the gold method. Histochemistry 77:37-50

Horishberger M, Tacchini-Vonlanthen M (1983b) Ultrastructural localization of Bowman-Birk inhibitor on thin sections of Glycine max (soybean) cv Maple Arrow by the gold method. Histochemistry 77:313-321

Hummel BCW (1959) A modified spectrophotometric determination of chymotrypsin, trypsin, and thrombin. Can J Biochem Physiol 37:1393-1399

Hwang DL, Yang WK, Foard DE (1978) Rapid release of protease inhibitors from soybeans. Plant Physiol 61:30-34

Kollipara KP (1992) Genetic, biochemical, and molecular studies of the Bowman-Birk inhibitors in the genus Glycine Willd. PhD Thesis, University of Illinois, Urbana-Champaign, Ilinois

Kollipara KP, Hymowitz T (1992) Characterization of trypsin and chymotrypsin inhibitors in the wild perennial Glycine species. J Agric Food Chem 40:2356-2363

Kollipara KP, Domagalski JM, Hymowitz T (1991) A quick method of resolving soybean Kunitz trypsin inhibitor using polyacrylamide gel electrophoresis. Soybean Genet Newslett 18:234-236

Kollipara KP, Singh RJ, Hymowitz T (1993) Genomic diversity in aneudiploid $(2 n=38)$ and diploid $(2 n=40)$ Glycine tomentella by cytogenetic and biochemical methods. Genome 36:391-396

Krishna TG, Reddy LJ (1982) Species affinities between Cajanus cajan and some Atylosia species based on esterase enzymes. Euphytica 31:709-713
Laemmli UK (1970) Cleavage of structural proteins during the assembly of the head of bacteriophage $T_{4}$. Nature 227:680-685

Liener IE (1986) Trypsin inhibitors: Concern for human nutrition or not? J Nutr 116:920-923

Liener IE, Kakade ML (1980) Protease inhibitors. In: Liener IE (ed) Toxic constituents of plant foodstuffs: 2 nd ed. Academic Press, New York, pp 7-71

Madden MA, Tan-Wilson AL, Wilson KA (1985) Proteolysis of soybean Bowman-Birk trypsin inhibitor during germination. Phytochemistry $24: 2811-2815$

Maesen LJG van der (1990) Pigeonpea: origin, history, evolution, and taxonomy. In: Nene YL, Hall SD, Sheila VK (eds) The pigeonpea. CAB Int, ICRISAT, India, pp 15-46

Mulimani VH, Paramjyothi S (1992) Proteinase inhibitors of redgram (Cajanus cajan). J Sci Food Agric 59:273-275

Mulvaney RL (1993) Mass spectrometry. In: Knowles R, Blackburn TH (eds) Nitrogen isotope techniques. Academic Press, San Diego, California, pp 11-57

Nadimpalli RG, Jarret RL, Phatak SC, Kochert G (1993) Phylogenetic relationships of the pigeonpea (Cajanus cajan) based on nuclear restriction fragment length polymorphisms. Genome 36 : 216-223

Nene YL, Sheila VK (1990) Pigeonpea: geography and importance. In: Nene YL, Hall SD, Sheila VK (eds) The pigeonpea. CAB Int, ICRISAT, India, pp 1-14

Odani S, Ikenaka T (1973) Scission of soybean Bowman-Birk proteinase inhibitor into two small fragments having either trypsin or chymotrypsin inhibitor activity. J Biochem 74:857-860

Pichare MM, Kachole MS (1992) Trypsin inhibitors of pigeonpea. Int Pigeonpea Newslett 16:20-22

Pundir RPS, Singh RB (1985) Biosystematic relationships among Cajanus, Atylosia and Rhynchosia species and evolution of pigeonpea [Cajanus cajan (L.) Millsp.]. Theor Appl Genet 69: $531-534$

Ryan CA (1990) Protease inhibitors in plants: genes for improving defenses against insects and pathogens. Annu Rev Phytopathol 28:425-449

Sakla AB, Ghali Y, El-Farra A, Rizk LF (1988) The effect of environmental conditions on the chemical composition of soybean seeds: deactivation of trypsin inhibitor and effect of microwave on some components of soybean seeds. Food Chem 29:269-274

Singh U (1988) Antinutritional factors of chickpea and pigeonpea and their removal by processing. Qual Plant Foods Human Nutr 38:251-261

Singh U, Eggum BO (1984) Factors affecting the protein quality of pigeonpea (Cajanus cajan L). Qual Plant Foods Human Nutr $34: 273-283$

Singh U, Jambunathan R (1981) Protease inhibitors and in-vitro protein digestibility of pigeonpea [Cajanus cajan (L.) Millsp.] and its wild relatives. J Food Sci Technol 18:246-247

Tan-Wilson AL, Wilson KA (1982) Nature of proteinase inhibitors released from soybean during imbibition and germination. Phytochemistry $21: 1547-1551$

Uriel J, Berges J (1968) Characterization of natural inhibitors of trypsin and chymotrypsin by electrophoresis in acrylamide-agarose gels. Nature 218:578-580

Weder JKP (1985) Chemistry of legume protease inhibitors and their use in taxonomy. Qual Plant Foods Human Nutr 35:183-194

Wilson KA, Papastoitsis G, Hartl P, Tan-Wilson AL (1988) Survey of the proteolytic activities degrading the Kunitz trypsin inhibitor and glycinin in germinating soybean (Glycine max). Plant Physiol 88:355-360

Zhang Y, Parsons CM, Hymowitz T (1991) Effect of soybeans varying in trypsin inhibitor content on performance of laying hens. Poultry Sci 70:2210-2213 